Case Report

\title{
Management of Complications Related to Laparoscopic Adjustable Silicone Gastric Band
}

\author{
Rodrigo Arrangoiz*, Manuel Muñoz-Juárez, Roger H. Pozzo, Fernando Cordera, \\ Enrique Luque-de León, Eduardo Moreno-Paquentin, M. Ángel Sánchez-Pérez, \\ Efrain Cruz-González, José David Hernández-Marín
}

Department of General Surgery at the American British Cowdray Medical Center, Mexico City, México

\section{Email address:}

rodrigo.arrangoiz@gmail.com (R. Arrangoiz),munozmd1@gmail.com (M. Muñoz-Juárez), fernando.cordera@gmail.com (F.Cordera), enrique.luque.d1@gmail.com (E. Luque-de León),1morenomd1@gmail.com (E. Moreno-Paquentin), cg_q_b@me.com (E.Cruz-González), dr.davidhm@outlook.com (J. D. Hernández-Marín)

${ }^{*}$ Corresponding author

\section{To cite this article:}

Rodrigo Arrangoiz, Manuel Muñoz-Juárez, Roger H. Pozzo, Fernando Cordera, Enrique Luque-de León, Eduardo Moreno-Paquentin, M. Ángel Sánchez-Pérez, Efrain Cruz-González, José David Hernández-Marín. Management of Complications Related to Laparoscopic Adjustable Silicone Gastric Band. Journal of Surgery. Vol. 5, No. 3, 2017, pp. 37-42. doi: 10.11648/j.js.20170503.11

Received: March 15, 2017; Accepted: April 5, 2017; Published: May 3, 2017

\begin{abstract}
Laparoscopic adjustable silicone gastric band (LASGB) is frequently used to treat morbidly obese patients worldwide. Complications related to this procedure have increased as the follow-up interval of these patients has increased. Treatment of these complications often includes removal of the silicone band. Herein we report our experience with silicone gastric band removal, discuss the different treatment alternatives, and present a management algorithm. A retrospective review of complications related to LASGB was made from June of 2003 to April of 2010 (eight patients). Techniques of band extraction are discussed and a management algorithm is presented. The mean Body Mass Index at the time of LASGB placement was 39.45 (Range 34.2 - 42.8). The median patient's age at the time of LASGB was of 32.6 years (range: 13 to 50 years). The average durability of the silicone band after laparoscopic placement was 67.8 months (range: 6 to 120 months). In three patients (37.5\%) the LASGB had perforated the gastric wall and was therefore extracted using a transgastric approach (laparoscopic in two patients and by laparotomy in one patient). In five patients the silicone band had not perforated the stomach and was therefore removed laparoscopically without entering the stomach. The weight was recovered in $37.5 \%$ of the patients during follow-up. Management of patients with complications related to LASGB placement must be individualized and should address both the band related complication as well as the obesity problem. Laparoscopic trans-gastric band extraction is ideal when the LASGB has eroded into the stomach and endoscopic extraction is not feasible.
\end{abstract}

Keywords: Laparoscopic Adjustable Silicone Gastric Band (LASGB), Gastric Perforation, Trans-Gastric Laparoscopy, Gastric Band Complication

\section{Introduction}

While laparoscopic adjustable silicone gastric band (LASGB) has been frequently used for the management of morbid obesity (MO) over the past decade in Mexico, Europe and Australia, experience with the procedure in the United States only dates back to the year 2001 [1-3]. Despite the widespread use of LASGB to treat obese patients in Mexico liberal use of the technique is to be condemned not only due to unproven long-term benefits but also due to potential postoperative complications. Late complications secondary to LASGB placement are now being observed more frequently in Mexico as the post-operative time interval has increased and it is anticipated that this same trend will be noted in other countries were LASGB use is more recent. The reported incidence of complications derived from the implantation of this device ranges from 5 to $40 \%$ and one of the most serious complications is erosion of the silicone band into the gastric 
lumen which can occur in up to $11 \%$ of patients [1-3]. Perforation of the stomach by the silicone prosthesis mandates band removal to avoid further complications. Silicone band removal can be accomplished through diverse therapeutic maneuvers including endoscopy, laparoscopy, and celiotomy or with a combined technique [2]. Herein we report our experience with silicone gastric band removal in eight patients, discuss the different alternatives of treatment, and present a management algorithm.

\section{Materials and Methods}

From June 2008 to April 2010 our surgical group practice based at the American British Cowdray Medical Center in Mexico City has been involved in the management of eight patients with LASGB related complications. In all cases, surgeons at other institutions had placed the adjustable silicone gastric band laparoscopically.

\section{Results}

The mean BMI at the time of LASGB placement was 39.45 (range: 34.2 - 42.8). Seven out of the eight patients were female $(87.5 \%)$. The median patient's age at the time of LASGB placement was 32.6 years (range: 13 to 50 years).

The average durability of the silicone band after laparoscopic placement in this group of patients was 67.8 months (range: 6 to 120 months). All patients underwent preoperative upper GI endoscopy and in three of the cases (37.5\%) the silicone band had perforated the gastric wall and was clearly visible within the stomach. Two of the patients, with gastric perforation, required an emergency operation (Table 1). In all of the patients with an internalized band the device was removed via a trans-gastric approach, either laparoscopically (in two patients) or by laparotomy (in one patient). In five of the cases the silicone band had not perforated the stomach and was therefore removed laparoscopically after dissecting peri-gastric adhesions without entering the stomach. In all cases the band was deflated and transected to facilitate removal. If a trans-gastric approach was elected, the site where the band enter was marked before band removal in order to secure proper obliteration of the tract and avoid a gastric leak. Subsequently, a longitudinal gastrotomy was performed in the anterior surface of the stomach as proximally as tissues were deemed adequate. The silicone band was then located within the stomach, grasped, cut and pulled out trough the gastrotomy. Intraoperative gastroscopy allows fixation of the gastroesophageal junction anteriorly and facilitates both, band identification and extraction. The silicone band was placed into a sterile plastic bag and extracted from the abdomen trough the umbilical port. The gastrostomy was closed with a laparoscopic lineal stapler and closure reinforced with a running layer of non-absorbable suture. After the silicone band was removed and the stomach repaired, integrity of the gastric wall was verified in all cases by intra-gastric instillation of methylene blue, a pneumatic test, and intraoperative upper endoscopy.

Postoperatively, an upper gastrointestinal study using Gastrografin was also used to document integrity of the stomach and lower esophagus. In our limited experience, there were no complications or mortality related to silicone band removal. On long-term follow-up, the only adverse effect noted was weight regain in three patients $(37.5 \%)$.

Results are not provided separately, rather they were incorporated under the heading of "Material \& Methods". A brief description of results along with references of tables and figures are required.

Table 1. Clinical presentation of patients with gastric wall erosion.

\begin{tabular}{|c|c|c|c|c|c|}
\hline PATIENT & GENDER & AGE & SYMPTOMS & DURATION & NOTES \\
\hline No. $1^{+}$ & $\mathrm{F}$ & 35 & $\begin{array}{l}\text { Dysphagia } \\
\text { Vomiting (30 times) }\end{array}$ & $\begin{array}{l}1 \text { month } \\
24 \text { hours }\end{array}$ & Dehydration Somnolence \\
\hline No. $2^{+}$ & $\mathrm{F}$ & 23 & $\begin{array}{l}\text { Acute epigastric pain } \\
\text { Abdominal tenderness }\end{array}$ & $\begin{array}{l}72 \text { hours } \\
12 \text { hours }\end{array}$ & Peritonitis in upper quadrants \\
\hline No.3 & $\mathrm{F}$ & 46 & Port infection Soft tissues infections & 2 months & Retired in 2002 Recurrent STI* \\
\hline
\end{tabular}

*STI $=$ Soft tissues infection. Include cellulitis and abscess formation in the site of subcutaneous tube (not retired with the port in 2002).

+ Patient was treated with emergency surgery.

\section{Discussion}

Obesity is a major healthcare problem worldwide that reduces the patient's quality of life in both industrialized and developing nations. Demographic studies show a recent increase in the prevalence of morbid obesity worldwide. This increase has been linked to changes in nutritional behavior [1, 4]. One of the most recent and careful global estimates finds that roughly 500 million adults are obese [25]. Linear time trend forecasts suggest that by $2030,51 \%$ of the population will be obese [26].

Conservative measures for weight reduction in patients with MO such as diet, behavioral modifications, or pharmacotherapy have high failure rates and have not demonstrated long-term substantial benefits $[5,6]$.

Nowadays, operative intervention is considered the most effective method for the treatment of MO. Surgery for obesity has demonstrated a reduction in both, obesity-related morbidity and mortality $[1,7]$.

In 2004, the American Society of Bariatric Surgery issued a review and made recommendations regarding current surgical techniques. Appropriate candidates for bariatric surgery should be MO, that is, to have a BMI $\geq 40$. Patients with a BMI $>35$ are appropriate surgical candidates when obesity-related comorbidities exist. Extending bariatric surgery to patients with $\mathrm{BMI}<35$ with severe comorbidities is 
the subject of clinical evaluation and is not routinely recommended at this time.

Bariatric operations include malabsorptive, malabsorptive combined with restrictive, and purely restrictive procedures. LASGB is a purely restrictive procedure. It is used mainly by some bariatric surgeons in Europe, Australia, and Mexico [1].

Laparoscopic adjustable silicone gastric band was first described by Belachew and colleagues in 1994 and is one of the option that bariatric surgeons have for the management of MO [8]. While LASGB has been frequently used for the management of MO over the past decade in Mexico, Europe, and Australia, experience with the procedure in the United States only dates back to year 2001 [1-3]. Early LASGB results show a trend toward a shorter in-hospital stay and lower morbidity when compared to other bariatric procedures. Studies show an expected weight loss of 18 to $59 \%$ and peri-operative mortality rate of $0.1 \%$ for this procedure [9, $10]$.

Failure of weight loss after placement of LASGB increases from about $15 \%$ during the first three years of follow-up up to $25 \%$ during the fourth year. Weight loss failure is approximately $30 \%$ during the fifth to seventh years after surgery and rises to approximately $40 \%$ during the years eighth and ninth after the operation [11].

The incidence of complications derived from this procedure ranges from 5 to $40 \%$ [1]. One of the most serious complications associated with gastric banding is erosion of the band into the gastric lumen [2], and its incidence ranges between $0.6 \%$ and $11 \%[2-4,11-17]$. After an initial tear of the serosal layer of the stomach, the band erodes the complete thickness of the gastric wall and enters the lumen. A study by Neville et al. showed that the most common site of erosion is in the left posterolateral wall of the stomach where the gastro-gastric fixation sutures are usually placed [14]. Inadvertent surgical gastric injury or gastro-gastric sutures overlying the locking mechanism of the band are thought to contribute to gastric erosion of the band [18]. Other possible contributing factors of transmural band penetration include: the abuse of nonsteroidal anti-inflammatory drugs, inflammatory response to foreign material such as silicone, chronic infection, noncompliant behavior from the patient, and frequent vomiting [6, 12, 18, 19].

Gastric erosion or perforation generally occurs 1.5 to 3 years after gastric band placement [2]. In our series, perforation occurred after six months of band placement in one patient, and after nine and 10 years in the other two patients. The clinical presentation of patients with LASGB related complications are usually nonspecific and may include abdominal pain, increased food consumption, cessation of weight loss, regain of lost weight [13], or may be as serious as sepsis due to peritonitis secondary to gastric perforation $[6,8$, $12,20,21]$. Other presenting symptoms include: loss of satiety, increase in weight, access port site infection, and lack of response to band adjustment [3]. Two patients of our series presented with acute symptoms related to gastric perforation: One patient (\#1) presented with a 24-hour history of vomiting, severe dehydration, and altered mental status. Another patient (\#2) presented with peritonitis. The third patient who had a gastric perforation (\#3) developed recurrent soft tissues infections at the port site and an abscess at this site that was drained and treated with antibiotics several times before referral to our surgical group.

The diagnosis of a LASGB-related complication is facilitated by ancillary studies including upper gastrointestinal contrast series, computed tomography scan, and upper endoscopy, the later providing the highest sensitivity of all [2, 3 , 13]. A pathognomonic finding in an upper gastrointestinal contrast study is visualization of the band as an intraluminal-filling defect. Nevertheless, this finding only occurs when at least $50 \%$ of the band has already migrated into the gastric cavity. An upper endoscopy with a retroflexed view allows direct visualization potentially eroded segments just below the gastroesophageal junction. Endoscopically, the erosion can be classified in 3 stages: Stage 1: a small part of the band is visible through a mucosal defect; Stage 2: more than half of the band has migrated in to the gastric cavity; and Stage 3: complete intragastric migration of the band. An upper GI endoscopy was routinely performed in all of our patients and demonstrated that the silicone band had perforated the stomach in three patients (Figures 1).

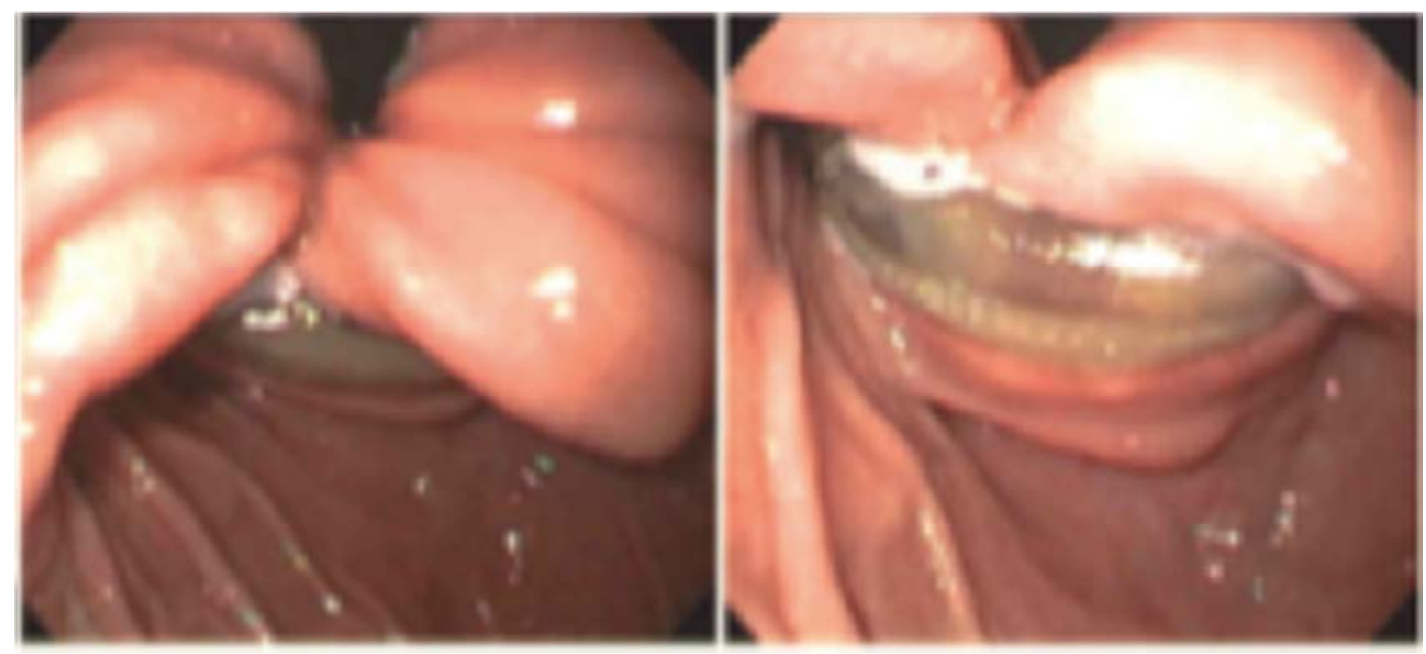

Figure 1. Endoscopic view showing gastric wall erosion secondary to gastric band device. 
CT findings may be subtle with minimal inflammatory changes at the gastric wall that may extend to a variable distance around the tubing and may even reach the port site leading to a fistula. Free gastric perforation may lead to obvious findings including intraperitoneal fluid, pneumoperitoneum or abscess formation [2, 6, 19, 20]. One of our patients had inflammatory changes around the tube with intraperitoneal fluid due to free gastric perforation while other presented a fistulous tract with recurrent soft infection of the abdominal wall corroborated by CT.

There are multiple options to achieve band removal. Therapeutic endoscopy may be used, but more commonly, the band is removed via laparoscopy or sometimes via laparotomy $[2,19]$ and even partial gastrectomy may be required [22]. The endoscopic approach for band removal is feasible when the band has already migrated almost completely into the gastric lumen. However, firm peritoneal adhesions can impede endoscopic extraction of the band and may lead to an urgent surgical procedure [13, 19].

Published experience regarding management of LASGB complications is sparse and limited to few reported cases of band removal without a definitive management consensus. Lattuada et al. reported successful endoscopic removal of five devices, two laparoscopically, and other two through laparotomy [19]. Bueter et al. reported laparoscopic band removal with closure of the gastric wall after band erosion [16] and Boschi et al. reported laparoscopic band removal with gastric closure using an Endo-GIA stapler [4]. In their study, Tolonen et al. performed band removal with simultaneous gastric bypass operation via laparotomy in three of four patients with gastric wall erosion [11]. Ayloo et al. reported a laparoscopic suture repair of the gastric wall with an omental patch and fibrin glue to seal the gastric perforation [23].

Other authors have recommended cutting the gastric mucosa endoscopically in two sessions and subsequently performing a 7-cm mini-laparotomy and a 3-cm gastrotomy to remove the band. The prosthesis can then be cut using scissors and gently pulled out through the gastrotomy. If a gastrotomy is required, it must be sutured and an endoscopic inspection must be performed [13]. Although Basa et al. recently reported for the first time in the literature a trans-gastric laparoscopic approach for gastric band removal [24] in one patient, we have successfully used this approach during the last six years in several patients. The feasibility and safety of LASGB removal via a laparoscopic trans-gastric approach in selected patients without complications after a median follow up of 30 months (Range: 2 to 78 months) in our practice advocates the use of this approach in those cases were the band has eroded the gastric wall into the lumen. In our experience, the approach for management of patients with late complications secondary to LASGB placement depends on several factors, but the following algorithm is currently used (Figures 2 and 3). Patients with late complications related to LASGB placement are initially divided into two groups; those that present with sepsis or peritonitis and those without an ongoing septic process. Patients in the former group are vigorously resuscitated, initiated in antimicrobials and promptly operated upon either laparoscopically or via laparotomy. Once the band is removed and the septic process is resolved, no further action is needed in the non-obese patient. Patients who continue to be morbidly obese are reevaluated and considered for elective bariatric procedure at a later date. Patients with late complications related to LASGB that present without sepsis or peritonitis are studied with an upper gastrointestinal contrast study, a computed tomography, and upper gastrointestinal endoscopy. These patients are further subdivided into morbidly obese and non-obese groups. If the patient is morbidly obese the standard protocol for bariatric surgery is applied and the silicone band is preferably removed and a gastric bypass operation is performed.

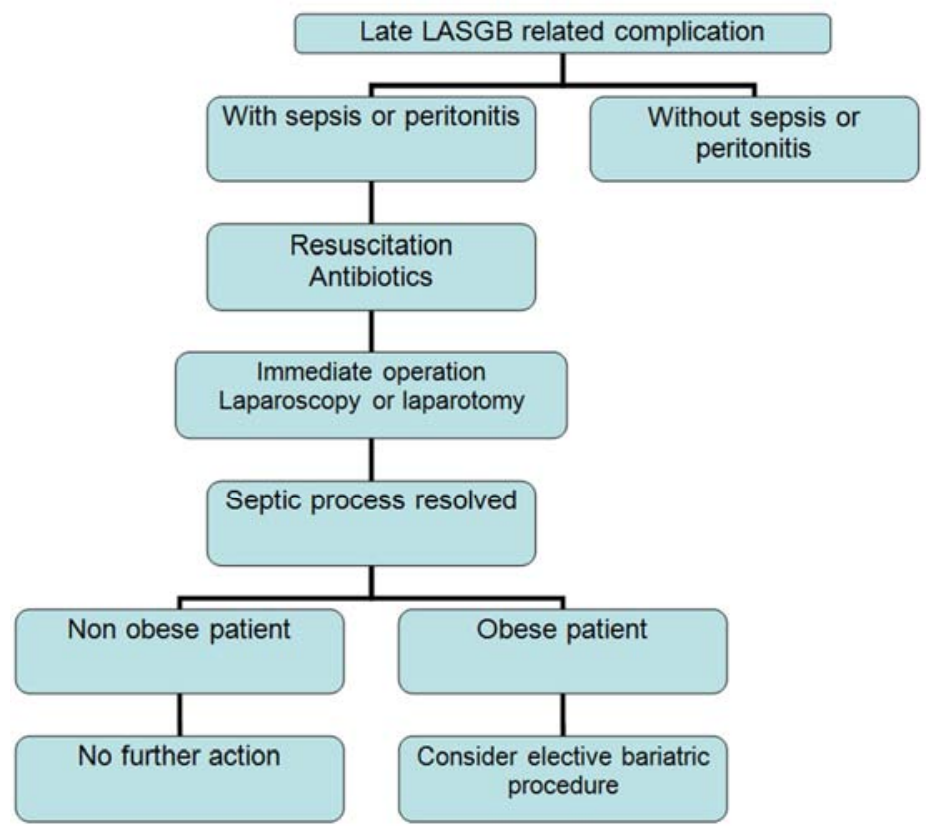

Figure 2. Management algorithm for late LASGB related complications in emergency cases. 


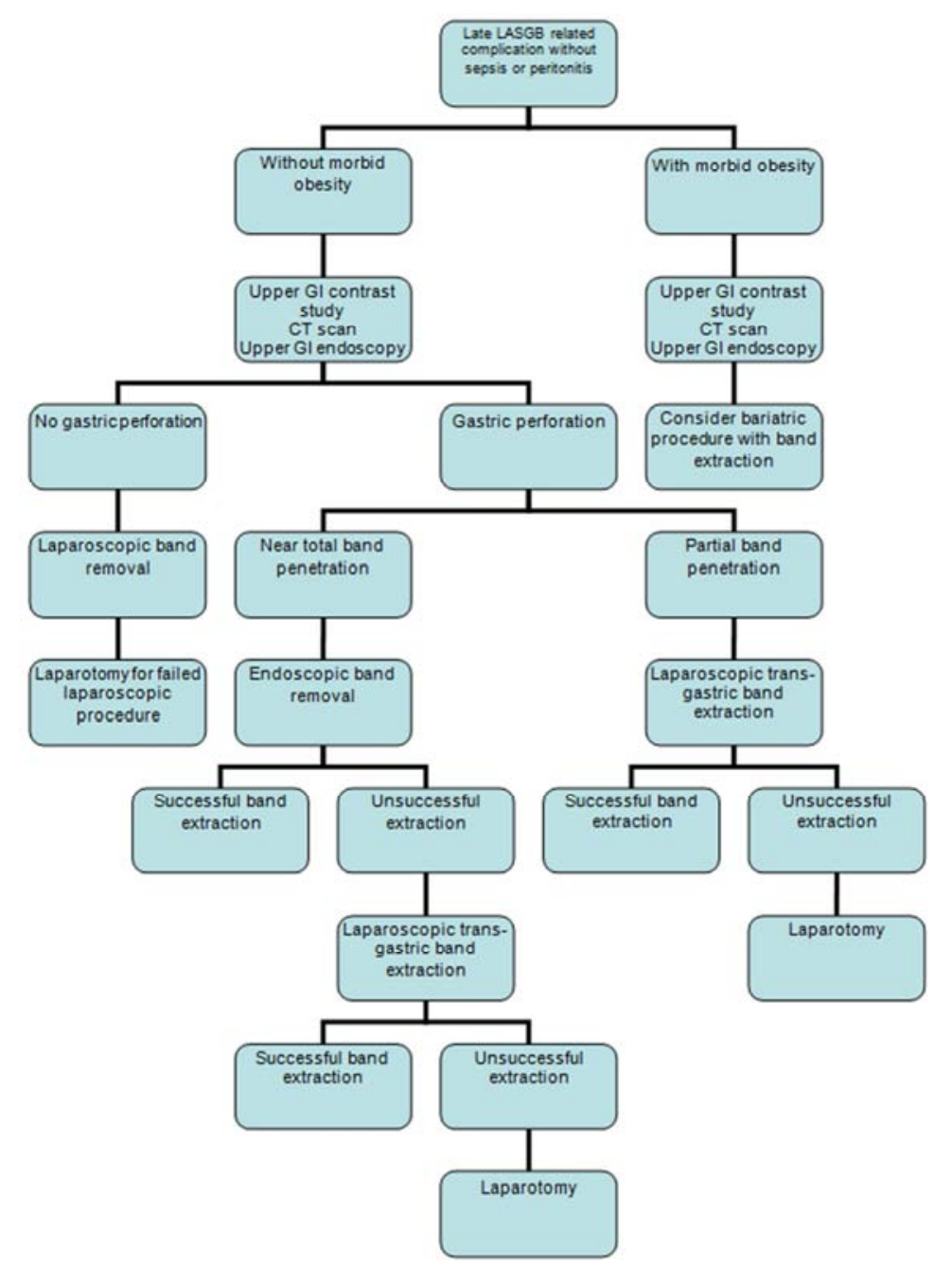

Figure 3. Management algorithm for late LASGB related complications in elective cases.

Non-obese patients with late complications related to LASGB without sepsis or peritonitis are studied and, in the absence of gastric perforation, laparoscopic silicone band removal is advised. Laparotomy is reserved for those patients in whom the band cannot be safely removed by the laparoscopic approach. If preoperative gastric perforation was detected and there is evidence that most of the band has entered the stomach the band should be removed by endoscopy preserving the laparoscopic trans-gastric approach or laparotomy for failed endoscopic extractions. If preoperative studies demonstrate that only a small portion of the band has eroded into the stomach the laparoscopic trans-gastric approach is the best alternative for band removal.

\section{Conclusion}

Liberal use of LASGB in non-MO patients should be discouraged due to potential postoperative complications. Management of patients with late complications secondary to LASGB placement must be individualized and should not only address the band related complication, but also the excess weight problem. Adequate management of late LASGB complications leads to minimal morbidity related to band removal. Special attention must be paid to avoid weight regain after LASGB removal.

\section{References}

[1] Ianelli A, Dahman M, Facchiano E, et al. A simple technique for laparoscopic removal of silicone adjustable gastric banding. J LaparoendoscopAdvSurg Tech 2006; 16:301-304.

[2] Chousleb E, Szomstein S, Lomenzo E, et al. Laparoscopic removal of gastric band after early gastric erosion. SurgLaparoscEndoscPercutan Tech 2005; 15:24-27.

[3] Sarker S, Herold K, Creech S, et al. Early and late complications following laparoscopic adjustable gastric banding. Am Surg 2004; 70:146-150.

[4] Boschi S, Fogli L, Berta R, et al. Avoiding Complications After Esophago-Gastric Banding: Experience with 400 Consecutive Patients. ObesSurg 2006; 16:1166-1170.

[5] Yurcisin BM, Gaddor MM, DeMaria EJ. Obesity and Bariatric Surgery. ClinChes Med 2009; 30:539-553.

[6] Caryccu L, Turner M, Szucs R. Adjustable Laparoscopic Gastric Banding for Morbid Obesity: Imaging Assessment and Complications. RadiolClin North Am 2007; 45:261-274. 
[7] Lee C, Kelly J, Wassel W. Complications of Bariatric Surgery. CurrOpinGastroenterol 2007; 23:636-643.

[8] Gagner M, Milone L, Yung E, et al. Causes of Early Mortality After Laparoscopic Adjustable Gastric Banding. J Am CollSurg 2008; 206:664-669.

[9] Ceelen W, Walder J, Cardon A, et al. Surgical Treatment of Severe Obesity With a Low-Pressure Adjustable Gastric Band. Experimental Data and Clinical Results in 625 Patients. Ann Surg 2003; 237(1):10-16.

[10] Ward M, Prachand V. Surgical Treatment of Obesity. GastrointestEndosc 2009; 70(5):985-990.

[11] Tolonen P, Victorzon M, Mäkelä J. 11-Year Experience with Laparoscopic Adjustable Gastric Banding for Morbid ObesityWhat Happened to the first 123 Patients? ObesSurg 2008; 18:251-255.

[12] Hainaux B, Agneessens E, Rubesova E, et al. Intragastric Band Erosion After Laparoscopic Adjustable Gastric Banding for Morbid Obesity: Imaging Characteristics of and underreported complication. AJR 2005; 184:109-112.

[13] Silecchia G, Restuccia A, Elmore U, et al. Laparoscopic Adjustable Silicone Gastric Banding: Prospective Evaluation of Intragastric Migration of the Lap-band. Surg Laparosc Endosc Percutan Tech 2001; 11(4):229-234.

[14] Niville E, Dams A, Valasselaers J. Lap-Band Erosion: Incidence and Treatment. ObesSurg 2001;11:744-747.

[15] Angus G, Rizvon K, Zhou D. Intra-Gastric Band Erosion from and Un-inflated Lap-Band: A Case Report. ObesSurg 2008; 18:1636-1639.

[16] Bueter M, Maroske J, Thalheimer A, et al. Short and Long-Term Results of Laparoscopic Gastric Banding for Morbid Obesity. Langenbecks Arch Surg 2008; 393-199-205.
[17] Dargent J. Isolated Food Intolerance After Adjustable Gastric Banding: A Long- Term Cause of Band Removal. ObesSurg 2008; 18:829-832.

[18] Wiesner W, Schob O, Hauser R, et al. Adjustable Laparoscopic Gastric Banding in Patients with Morbid Obesity: Radiographic Management, Results and Postoperative Complications. Radiology 2000; 216:389-394.

[19] Lattuada E, Zappa M, Mozzi E, et al. Band Erosion Following Gastric Banding: How to Treat It. ObesSurg 2007; 17:329-333.

[20] Allen J. Laparoscopic Gastric Band Complications. Med Clin N Am 2007; 91: 485-497.

[21] Cortés A, Navarrete G, Fuente-Alba S. Gastric Band Erosion as complication of bariatric surgery. Case Report and Review of the Literature. GastroenterolHepatol 2007; 30(8):465-468.

[22] Abu-Abeid S, Szold A. Laparoscopic Management of Lap-Band Erosion. ObesSurg 2001; 11:87-89.

[23] Ayloo S, Bueno R. Band Erosion: Laparoscopic removal of lap band. SurgEndosc 2009;23(6):657-658.

[24] Basa N, Dutson E, Lewis C, et al. Laparoscopic Transgastric Removal of Eroded Adjustable Gastric Band: A Novel Approach. SurgObesRelat Dis 2008; 4(2):194-197.

[25] Finucane MM, Stevens GA, Cowan MJ, et al. National, regional, and global trends in body-mass index since 1980: systematic analysis of health examination surveys and epidemiological studies with 960 country-years and 9.1 million participants. Lancet. 2011; 377:557-67.

[26] Finkelstein EA, Khavjou OA, MA, Thompson H, Trogdon JG, Pan Liping, et al. Obesity and Severe Obesity Forecasts Trough 2030. Am J Prev Med 2012; 42(6):563-570. 